\title{
A prediction model for the dynamic mechanical degradation of sedimentary rock after a long-term freeze-thaw weathering: considering the strain-rate effect
}

\author{
Peng Wang ${ }^{1 *}$, Jinyu Xu ${ }^{1,2}$, Shi Liu ${ }^{1}$, Shaohe Liu ${ }^{1}$, Haoyu Wang ${ }^{1}$ \\ 1. Department of Airfield and Building Engineering, Air Force Engineering University, Xi'an, Shaanxi, China \\ 2. College of Mechanics and Civil Architecture, Northwest Polytechnic University, Xi'an, Shaanxi, China
}

\begin{abstract}
:
Rock engineering and stone construction in cold region are always suffering the recurrent freeze-thaw (F-T), and rock mechanical behaviors in projects usually involve responses to stress pulses or impact loads due to the widely existed blasting operation, mechanized construction and seismic oscillation. In this work, physical tests as well as static and impact mechanical experiments were carried out on red-sandstone free from and after F-T weathering. Totally five specimen groups were prepared for static and dynamic compressive tests respectively, of which one group was water-saturated and free from F-T, and four groups were water-saturated and then respectively suffered by 5, 10, 15, 25 cycles of artificial F-T. Changes of physico-mechanical properties of red-sandstone after F-T cycles, including density, porosity, P-wave velocity, uniaxial compressive strength (UCS) and deformation modulus ( $\mathrm{E}_{\mathrm{d}}$ ), illustrated the F-T induced damages of sedimentary rock. For a better predicting of the dynamic mechanical degradation of sedimentary rock after a long-term F-T weathering, decay models of mechanical properties reflecting the strain rate effects were built.
\end{abstract}

The UCS and $E_{d}$ were adopted as the integrity indexes of rock in the decay model, and the model parameters, decay

\footnotetext{
* Corresponding author: P. Wang

E-mail address: wpsuai@126.com
} 
constant $(\lambda)$ and half-life $\left(\mathrm{N}_{1 / 2}\right)$ were expressed as functions of strain rate.

\section{Keywords:}

Freeze-thaw weathering; the decay model; rock impact dynamics; SHPB; strain rate effect

\section{Introduction}

Exposed to the earth's water and atmosphere, rocks are always suffering various kinds of weathering. Cycling freeze-thaw (F-T) is a common and serious rock weathering factor in cold region (Yatsu, 1988), where the environment temperature floats up and down the freezing point of water. F-T induced deterioration of rock is crucial concern during the preliminary design, project construction and maintenance stages of cold region geotechnical works (Shen, 2004; Zhang, et al., 2004; Lai, et al., 2012).

F-T weathering has long been discussed as a major physical deterioration process. F-T induced changes of physical and mechanical properties of various rocks have been investigated (Nicholson, et al., 2000; Ruedrich, et al., 2011; Tan, et al., 2011), including density, porosity, P-wave velocity, point load strength, uniaxial compressive strength (UCS), etc.. The frequent freezing and thawing of pore water inside rock expands the cracks and pores and promotes the development of new micro-fractures (Park, et al., 2015) and thus does great damage to rock engineering (Sousa, et al., 2005). Despite the extensive use of accelerated weathering tests in durability assessments (Altindag, et al., 2004; Benavente, et al., 2004; Akin and Ozsan, 2011; Tan, et al., 2011), it's insufficient to evaluate the long-term durability of rocks. As a result, many decay models (Mutlutürk, et al., 2004; Fatih, 2012; Liu, et al., 2015) were built by scholars to analyze the durability of rocks suffered a long-term weathering. Mutlutürk, et al. (2004) proposed a decay model that uses the decay constant $(\lambda)$ and half-life $\left(\mathrm{N}_{1 / 2}\right)$ parameters to express the disintegration rate of rock. This decay model fitted the test results well and was much more concise, and was adopted widely (Jamshidi, et al., 2013; Khanlari, et 
al., 2015). However, almost no decay models take the strain rate effect into consideration and predict the dynamic mechanical degradation of rocks after a long-term freeze-thaw weathering.

In fact, because of the extensively existed blasting operation, mechanized construction as well as seismic oscillation, rock engineering disasters often involve rock responses to stress pulses or impact loads, and the corresponding prevention and cure researches come down to the analyses on dynamic mechanical properties of rock-like materials ( $\mathrm{Li}$ and $\mathrm{Gu}, 1994$; Zhang and Zhao, 2014). Stain rate is a key factor to the mechanical properties of rock-like materials, which could change the strength and deformation characteristics substantially. Rock behaviors under different strain rate varied a lot and these differences are enough to change the rock responses to loads or weathering environments. Due to the rate sensitivity, dynamic mechanical behaviors of rocks after F-T weathering differ from those presented under static loading conditions. Literature reviews show that investigations about the F-T weathering are concentrated on physical and static mechanical properties (Yavuz, et al., 2006; Ghobadi and Babazadeh, 2015), only a few works have been published about the dynamic mechanical behaviors of F-T weathered rock. Wen et al. (2015) obtained the relationship between the dynamic strength and the freeze-thaw cycles according to the results of numerical simulations and experiments. Zhou, et al. (2015) obtained the microscopic damage characteristics and dynamic mechanical parameters of sandstone after freeze-thaw from the nuclear magnetic resonance (NMR) tests and impact loading tests. Investigations about the effects of F-T cycles on the rock dynamic mechanical properties during the weathering process are far from enough.

Sedimentary rock distributes extensively in the superficial lithosphere, of which the distribution area is the main provider of minerals and the main place of human beings for engineering geological and hydrogeological works. Due partly to the mineral composition and porous structure, sedimentary rock is generally more affected by F-T weathering. For a deeper understanding of F-T effects on the static and 
dynamic mechanical properties, predicting the dynamic mechanical degradation of sedimentary rock after a long-term freeze-thaw weathering, static and dynamic compressive experiments on red-sandstone, a common sedimentary rock, free from and after cycling F-T were carried out in this work. Totally five groups of specimens were prepared for static compression and dynamic impact tests respectively, of which one group was water-saturated and free from F-T weathering, while the other four groups were water-saturated and then respectively suffered 5, 10, 15, 25 artificial F-T cycles. Impact loading tests were carried out using the split Hopkinson pressure bar (SHPB) system (Xia and Yao, 2015), with the impact condition set at five strain rate grades. Decay models of dynamic mechanical properties reflecting the strain rate effects were built, and the model parameters were identified based on experimental results. Influences of strain rate on the model parameters were analyzed.

\section{Material and methods}

\subsection{Red-sandstone specimen preparation}

Red-sandstone in this work was quarried from the underground construction field in the Hengduan Mountains, located at the southeastern corner of the Qinghai-Tibet plateau in China. It is a typical kind of sedimentary rock, with a uniform red surface. With the determination environment set at $25^{\circ} \mathrm{C}$ and $40 \%$ humidity, X-ray diffraction analysis was carried out to determine the mineral composition of red-sandstone samples, as listed in Table 1.

Table 1 Mineral composition of red-sandstone in this paper

\begin{tabular}{cccccccc}
\hline Composition & quartz & plagioclase feldspar & potash feldspar & calcite & chlorite & illite & hematite \\
\hline Content $/ \%$ & 81 & 10 & 3 & 3 & 1 & 1 & 1 \\
\hline
\end{tabular}

Red-sandstone was made into standard cylinder specimens, $\Phi 96 \times 48 \mathrm{~mm}$, for dynamic impact compression tests. Attention was paid to prepare red-sandstone samples which were free from visible defects 
and flaws, and ultrasonic detection was performed during the selection to minimize differences between specimens used in tests.

\subsection{Accelerated F-T weathering}

Followed the boiling water saturation method, as introduced in the DL/T 5368-2007 (National Development and Reform Commission of the People's Republic of China, 2007), red-sandstone specimens were water-saturated before the F-T weathering tests. Artificial F-T weathering tests were carried out using an automatic cycling F-T machine (Fig.1), with the temperature control program set as Fig.1: a 4-h freezing period after the test chamber temperature reaching the preset value $\left(-20^{\circ} \mathrm{C}\right)$, followed by a 4-h thawing period during which the specimens were immersed in water at $20^{\circ} \mathrm{C}$. These were considered as one F-T cycle. In this work, four experimental groups were carried out with the F-T cyclic number set as 5, 10, 15, 25 respectively, and one control group was designed with the specimens saturated and free from F-T weathering. Since Newton's Law of Heating and Cooling applied to those F-T cycles, the temperature changes followed almost the same path during each cycle (see Fig.1) for cycling F-T tests (Mutlutürk, et al., 2004).
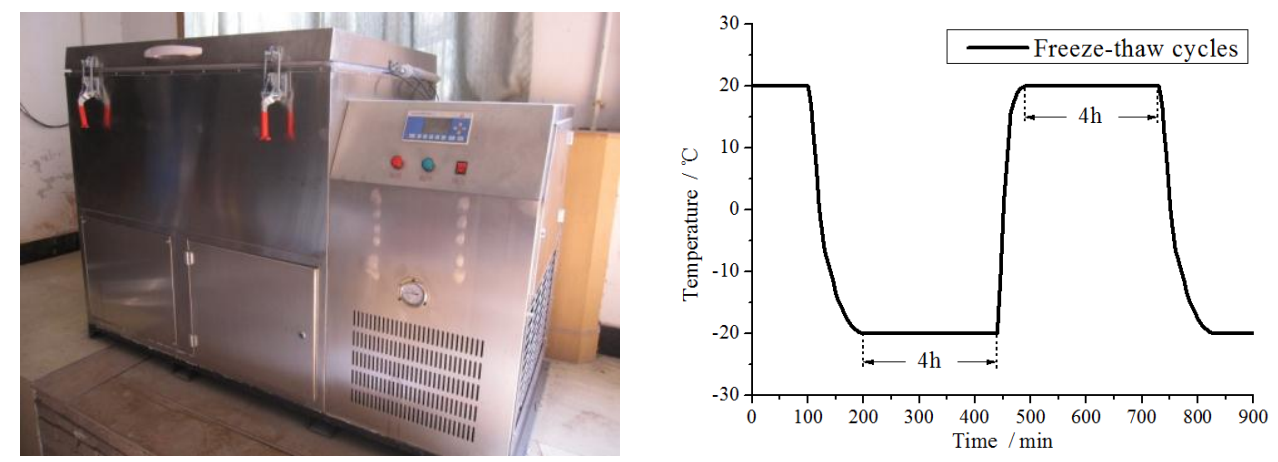

Fig.1. The automatic cycling F-T machine and the temperature schematic diagram of accelerated F-T

Except for a short time for the nondestructive physical determination, red-sandstone specimens were kept in water at $20^{\circ} \mathrm{C}$ after F-T weathering tests, till surface-wiped for the loading tests. The whole mechanical experiments were carried out also at room temperature $\left(20^{\circ} \mathrm{C}\right)$. 


\subsection{Index property determination}

F-T weathering involves disintegration in index properties of rocks. Therefore, comparison between index properties measured before and after F-T tests can be used to quantify the weathering degree. In this study, F-T weathering effects on index properties were investigated by measuring the block density, porosity, P-wave velocity and static UCS of fresh and deteriorated rocks.

\subsubsection{Bulk density and porosity}

Determination of bulk density, as the ratio of the saturated mass to bulk volume, was applied on red-sandstone samples before and after F-T weathering.

The total porosity and effective porosity of red-sandstone samples were determined using buoyancy techniques, as recommended by ISRM (1981). The total porosity and effective porosity calculation are as follows:

$$
\phi=\frac{M_{s a t}-M_{d r y}}{M_{s a t}-M_{w}} \times 100 \% ; \quad \phi_{e}=\frac{M_{w e t}-M_{d r y}}{M_{s a t}-M_{w}} \times 100 \%
$$

where $\phi$ signifies total porosity, i.e., the ratio of total pore volume to bulk sample volume; $\phi_{e}$, named effective porosity, indicates the volume ratio of opened voids to the entire rock sample; $M_{\text {sat }}$ is the saturated-surface-wiped mass of specimen saturated through boiling water saturation method; $M_{d r y}$ is the mass of specimens completely dried; $M_{\text {wet }}$ is the wet-surface-wiped mass of specimen after 48-h of unforced water absorption; $M_{w}$ is the saturated-submerged weight measured with the saturated red-sandstone specimen immersed in water. Meanwhile, it should be pointed out that, the "degree of saturation (Sr )" (Brown, 1981) of saturated specimen prepared as the method in this paper was supposed to be $100 \%$, which was theoretically hard to reach completely.

Porosity characteristics of red-sandstone samples were determined before artificial F-T. For experimental 
groups after F-T, reserved specimens which suffered F-T weathering but free from destructive loading tests were set aside to determinate the porosity properties again with the same methods as above-mentioned.

\subsubsection{Ultrasonic inspection}

Ultrasonic longitudinal wave testing was applied on the samples prior to and after F-T weathering. The direct method proposed by Kahraman (2002) was adopted and a nonmetal supersonic test meter with two transducers of $50 \mathrm{kHz}$ was used to detect the P-wave velocity of red-sandstones. To improve the sample-header contact, vaseline was distributed on the interface as the ultrasonic coupling fluid.

\subsubsection{Static compressive tests}

Static uniaxial compressive tests were done by hydraulic servo material testing system, with the loading rate set at $0.16 \sim 0.18 \mathrm{MPa} / \mathrm{s}$ (Bieniawski and Bernede, 1979). Three samples were prepared for each control or experimental groups in the static loading tests. In this paper, the maximum axial stress during the compression progress was regarded as the static UCS of the red-sandstone specimens.

\subsection{Dynamic mechanical experiments}

Following the ISRM suggested methods (Zhou et al., 2012), the $\Phi 100 \mathrm{~mm}$ SHPB system was applied to the uniaxial impact compressive tests, of which the photograph and basic principles were shown in Fig.2.
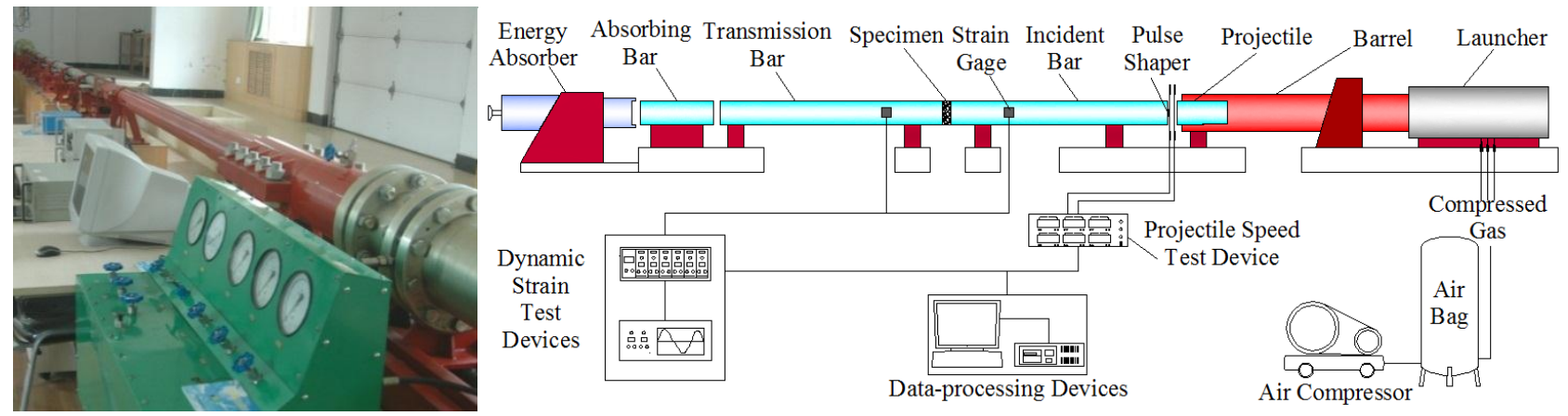

Fig.2. The $\Phi 100 \mathrm{~mm}$ SHPB test system photograph and schematic diagram 
Dynamic equilibrium and deform uniformity are required within the impact deformation duration of specimen. For guarantee, pulse shaping technique was adopted and a circular annealed T2 copper pulse shaper, $1.0 \mathrm{~mm}$ in thick and $15-35 \mathrm{~mm}$ in diameter, was placed on the impact surface of the incident bar. In the SHPB impact test, incident wave generated by the strike of projectile against the incident bar propagates along the incident bar, reflects and transmits at the "bar-specimen-bar" interface, during which process, information of incident wave, reflected wave and transmitted wave is collected by strain gages, as shown in Fig.3. Rock is a typical rate-sensitive material, and strain rate is of crucial influence on its dynamic mechanical behaviors. In this work, strain rate was selected as the main control factor in the impact tests. By adjusting the incident wave intensity, the average strain rate of red-sandstone specimens for each group was controlled to five levels, $213 \mathrm{~s}^{-1}, 273 \mathrm{~s}^{-1}, 303 \mathrm{~s}^{-1}, 350 \mathrm{~s}^{-1}$ and $422 \mathrm{~s}^{-1}$.

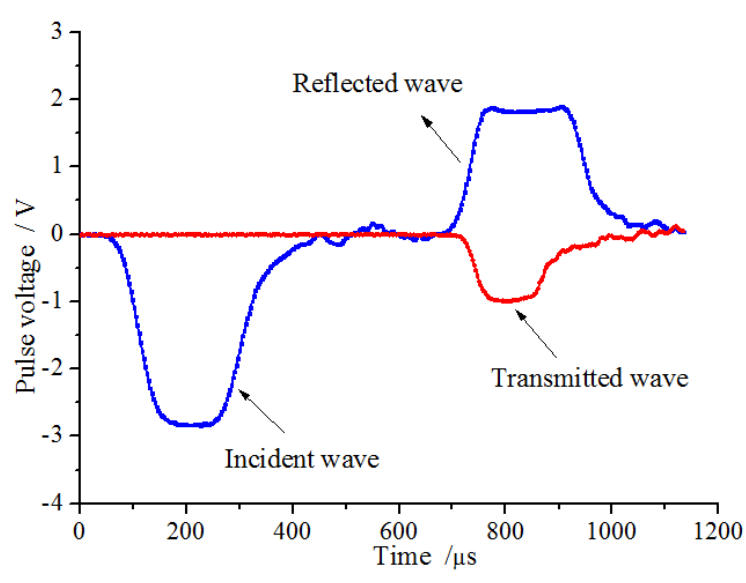

Fig.3. Typical pulse waves recorded by strain gages

Rely on the one-dimensional elastic stress wave assumption, the basic principle of SHPB test, the dynamic stress-strain relation of specimen can be calculated using the recorded wave signals, incident wave, reflected wave and transmitted wave (Frew, et al., 2001). Dynamic mechanical indexes such as dynamic UCS (peak stress), the maximum axial stress of specimen during the impact compression progress, and dynamic critical strain $\left(\varepsilon_{c}\right)$, the axial strain value of specimens at peak stress point, were obtained from the stress-strain relations. The dynamic deformation modulus $\left(E_{d}\right)$, a measure of the resistance to deformation 
during the whole pre-peak stage, was calculated as the ratio of UCS to $\varepsilon_{c}$.

\section{Results and analyses}

In cold region, driven by temperature variation around the freezing point, phase transition of water-ice occurs to water located in pores and adsorbed on mineral grains inside rocks, which has a great impact on the rock properties (Davidson and Nye, 1985).

\subsection{Deterioration of index properties after F-T weathering}

Physical measurement results of red-sandstone before and after F-T weathering were averaged in Table 2, along with the relative variation percentages. Suffered by artificial F-T, red-sandstone changed in almost all physical parameters, among which the saturated mass, bulk density and P-wave velocity decreased, and the bulk volume, effective porosity and total porosity increased with the adding-up of F-T cycles.

Table 2 Averages and relative variations of physical properties of red-sandstone before and after F-T weathering

\begin{tabular}{|c|c|c|c|c|c|c|c|c|c|}
\hline \multirow{3}{*}{$\begin{array}{c}\text { F-T } \\
\text { cyclic } \\
\text { number }\end{array}$} & \multicolumn{3}{|c|}{ Saturated mass } & \multicolumn{3}{|c|}{ Bulk volume } & \multicolumn{3}{|c|}{ Bulk density } \\
\hline & Before & After & Variation & Before & After & Variation & Before & After & Variation \\
\hline & \multicolumn{2}{|c|}{$\mathrm{g}$} & $\%$ & \multicolumn{2}{|c|}{$\mathrm{cm} 3$} & $\%$ & \multicolumn{2}{|c|}{$\mathrm{g} / \mathrm{cm} 3$} & $\%$ \\
\hline 0 & 810.4 & - & 0 & 338.8 & - & 0 & 2.39 & - & 0 \\
\hline 5 & 810.8 & 808.1 & -0.33 & 340.2 & 345.1 & 1.44 & 2.38 & 2.34 & -1.75 \\
\hline 10 & 812.5 & 808.2 & -0.53 & 340.5 & 347.7 & 2.09 & 2.39 & 2.32 & -2.57 \\
\hline 15 & 809.4 & 800.6 & -1.09 & 339.3 & 349.5 & 3.01 & 2.39 & 2.29 & -3.98 \\
\hline 25 & 812.9 & 799.3 & -1.67 & 340.6 & 353.3 & 3.73 & 2.39 & 2.26 & -5.21 \\
\hline
\end{tabular}

Continued Table 2 Averages and relative variations of physical properties of red-sandstone before and after F-T weathering

\begin{tabular}{|c|c|c|c|c|c|c|c|c|c|}
\hline \multirow{3}{*}{$\begin{array}{c}\text { F-T } \\
\text { cyclic } \\
\text { number }\end{array}$} & \multicolumn{3}{|c|}{ Effective porosity } & \multicolumn{3}{|c|}{ Total porosity } & \multicolumn{3}{|c|}{ P-wave velocity } \\
\hline & Before & After & Variation & Before & After & Variation & Before & After & Variation \\
\hline & \multicolumn{2}{|c|}{$\%$} & $\%$ & \multicolumn{2}{|c|}{$\%$} & $\%$ & \multicolumn{2}{|c|}{$\mathrm{m} / \mathrm{s}$} & $\%$ \\
\hline 0 & 11.0 & - & 0 & 15.8 & - & 0 & 2968.0 & - & 0 \\
\hline 5 & 11.3 & 13.8 & 22.16 & 15.6 & 17.3 & 10.38 & 2965.5 & 2445.4 & -17.54 \\
\hline 10 & 10.9 & 13.8 & 25.90 & 15.7 & 17.7 & 12.98 & 2967.8 & 2173.7 & -26.75 \\
\hline 15 & 11.2 & 15.0 & 33.39 & 16.1 & 19.2 & 19.02 & 2964.2 & 1812.8 & -38.84 \\
\hline 25 & 10.8 & 15.8 & 45.87 & 15.8 & 20.5 & 29.46 & 2970.9 & 1470.6 & -50.50 \\
\hline
\end{tabular}

Histograms in Fig.4 presented much more vividly the relative variations of physical properties after 5, 10, 
15, 25 F-T cycles. With the increase of artificial F-T cycles, variations of main physical indexes were accumulated. Cycling F-T weathering caused the mass loss and volume expansion, thus reduced the bulk density. For specimens after 5 and 25 F-T cycles respectively, saturated mass lost $0.33 \%$ and $1.67 \%$ in average, while block volume expanded $1.44 \%$ and $3.73 \%$, and the apparent density inevitably reduced by $1.75 \%$ and $5.21 \%$. F-T cycles promoted the development of fractures and holes and therefore increased the total porosity. The total porosity increased by $10.38 \%$ after 5 cycles of F-T, by $19.02 \%$ after 15 F-T cycles and by $29.46 \%$ after 25 F-T cycles. In addition to this, F-T weathering also improved the pore connectivity. Compared to the total porosity, the effective porosity grew by a larger range, $22.16 \%$ after 5 cycles of F-T, by $33.39 \%$ after 15 F-T cycles and by $45.87 \%$ after 25 F-T cycles. Another obvious index disintegration of red-sandstone after F-T weathering was the reduce of P-wave velocity, by $17.54 \%$ after 5 cycles of F-T, by $38.84 \%$ after 15 F-T cycles and by $50.50 \%$ after 25 F-T cycles. Variations of most of the index properties showed characteristics that changed faster in the first few cycles of F-T and got slower with the increase of cyclic number.

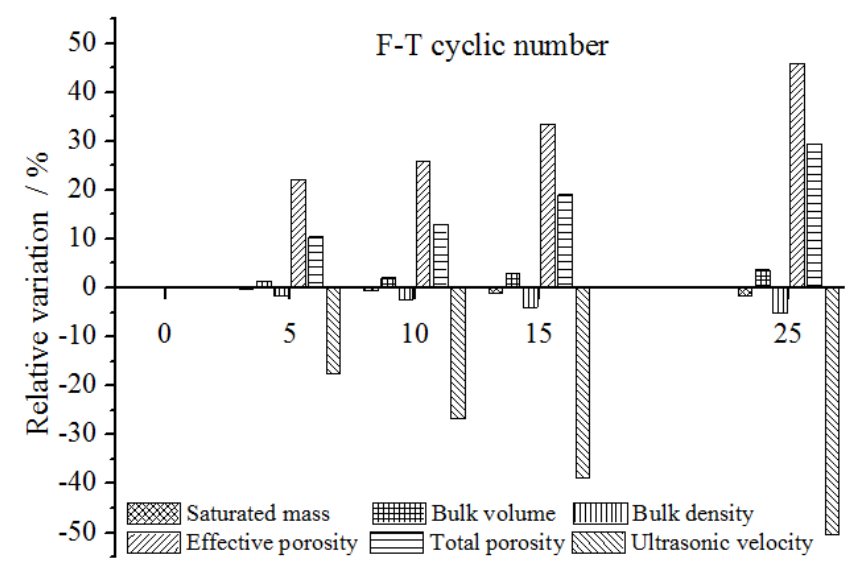

Fig.4. Relative variations of physical indexes of red-sandstone after F-T cycles, measured in saturated state

Due to the direct practical relevance to rock engineering applications, static UCS is more favorably investigated as characterization of rock bearing capacity. To indicate the relative residual strength after F-T cycles, the coefficient of frost resistivity $\left(C_{f}\right)$ was defined in this work as the static UCS ratio of specimens after different F-T cycles to specimen free from F-T, often expressed as a percentage. As shown in Fig.5, great 
decrease of static UCS occurred to red-sandstone during the process of cyclic F-T, although the decrease rate was slowing down. An exponential function, Eq.(2), fitted well on the $C_{f}$ of red-sandstone in this work, of which the coefficient of determination $\left(\mathrm{R}^{2}\right)$ reached 0.999 .

$$
C_{f}=49.4+50.6 e^{-0.07 N}, \quad R^{2}=0.999
$$

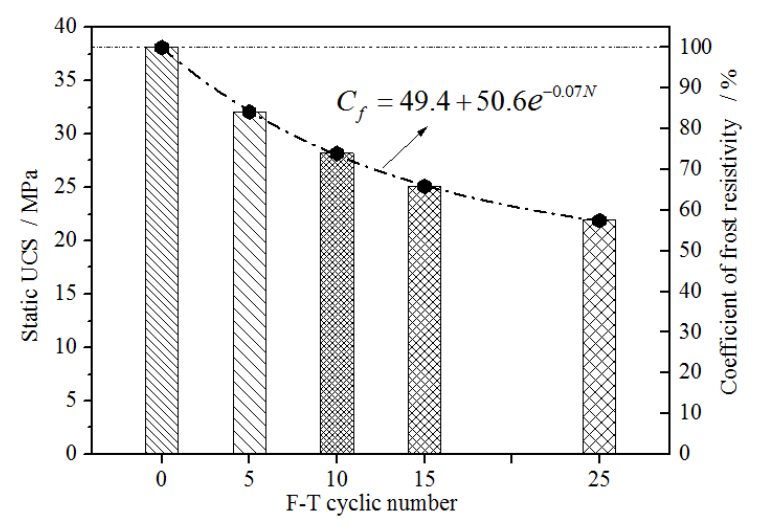

Fig.5. Static UCS and $\mathrm{C}_{\mathrm{f}}$ versus F-T cyclic number

After 5, 10, 15 and 25 F-T cycles, static UCS of red-sandstone reduced respectively to $84.2 \%, 74.0 \%$, $65.9 \%$ and $57.5 \%$ of un-weathered specimens, of which the average static UCS was 38.13MPa. The strength reduction of F-T weathered specimens can be attributed to the F-T induced attenuation of the solid skeleton and consolidation between mineral grains.

\subsection{Dynamic mechanical properties free from or after F-T weathering}

Based on the recorded incident wave, reflected wave and transmitted wave, dynamic stress-strain relations of red-sandstones were calculated and drawn in Fig.6. In Fig.6, (a), (b), (c), (d) and (e) respectively presented the typical stress-strain curves of specimens at strain rate close to $213 \mathrm{~s}^{-1}, 273 \mathrm{~s}^{-1}, 303 \mathrm{~s}^{-1}, 350 \mathrm{~s}^{-1}$, $422 \mathrm{~s}^{-1}$. For each strain rate group, curves of specimens free from and suffered 5, 10, 15, 25cycles of F-T were drawn. The curves clearly showed the nonlinear and plastic characteristics during the deformation process of red-sandstone. Compression phase was obvious for most of the red-sandstone groups, where the specimens 
generated large plastic deformation (Wang, et al., 2015).
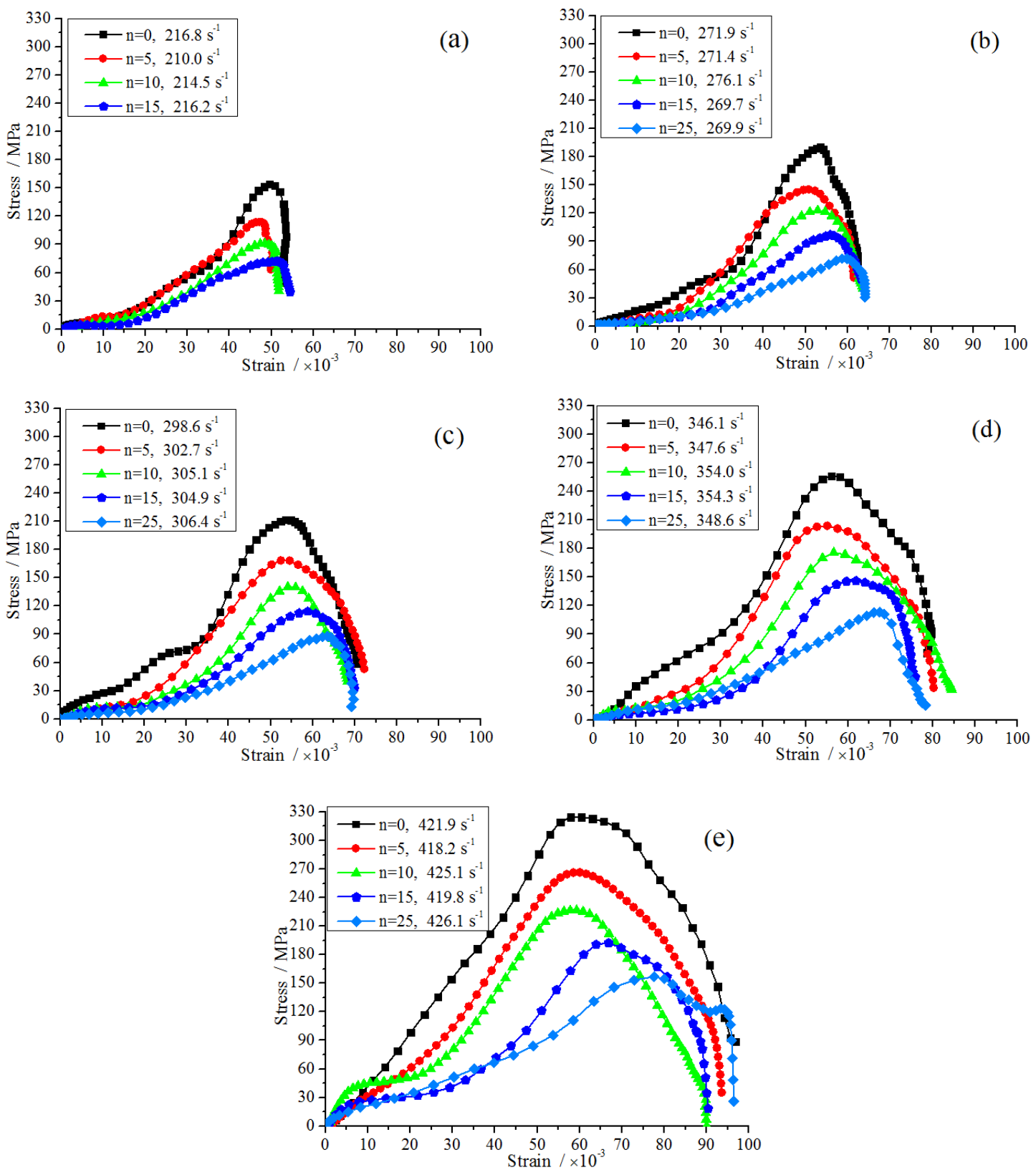

Fig.6. Stress-strain curves of red-sandstone suffered different cycles of F-T: (a) At strain rate close to $213 \mathrm{~s}^{-1}$; (b) At strain rate close to $273 \mathrm{~s}^{-1}$; (c) At strain rate close to $303 \mathrm{~s}^{-1}$; (d) At strain rate close to $350 \mathrm{~s}^{-1}$; (e) At strain rate close to $422 \mathrm{~s}^{-1}$

Peak stress and deformation modulus of red-sandstones at different strain rates were respectively drawn in Fig.7(a) and (b) versus F-T cyclic number, among which stress and modulus data of specimens at strain rate of $10^{-5} \mathrm{~s}^{-1}$ were obtained from static compressive tests and others from impact compressive tests. UCS represented the carrying capacity and the deformation modulus stood for the ability to resist deformation. 
Both these two important mechanical indexes went down with the adding up of the F-T cycles. For saturated red-sandstone in this paper, comparatively large decreases of UCS and modulus arose from the first few cycles of F-T, and the reducing rate slowed down during the following F-T cycles. Obviously, the cyclic freeze-thaw did great damage to red-sandstone specimens, resulting to the decreases of UCS and deformation modulus. As for the slowing down of decrease speeds with the adding-up of F-T number, a likely reason was that micro-cracks caused by the first few F-T cycles could release stress to a certain extent during the later F-T cycles.
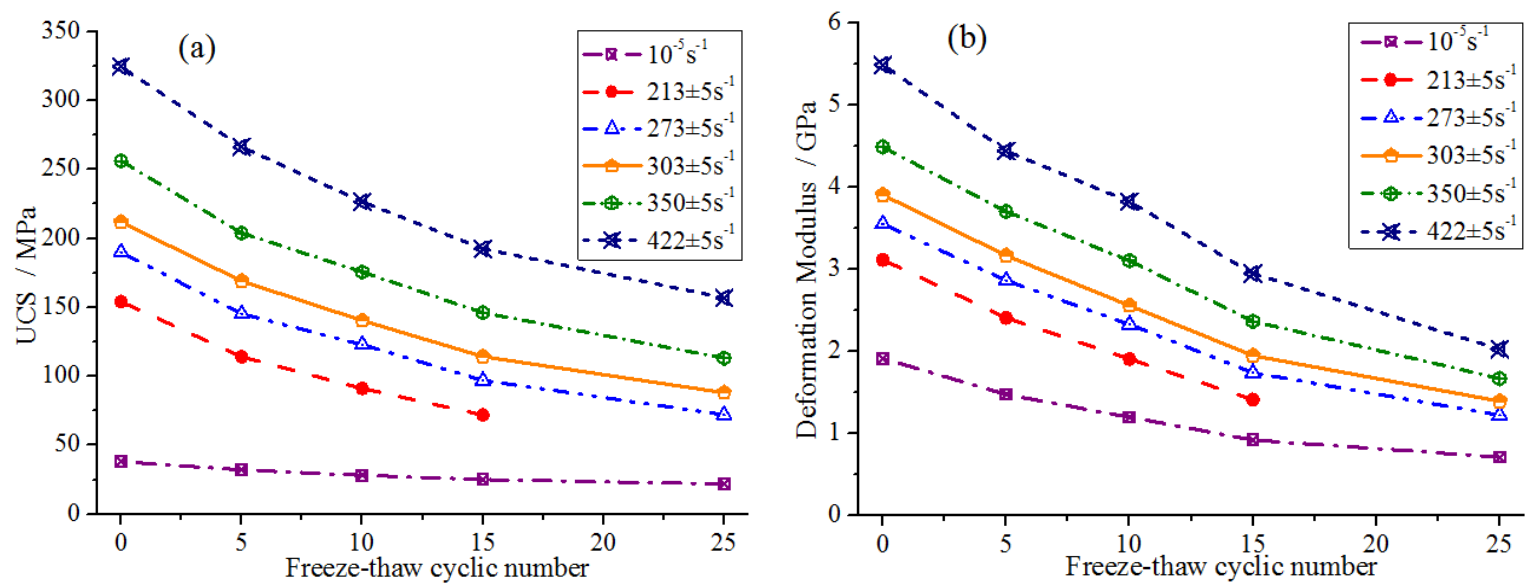

Fig.7. UCS and deformation modulus of red-sandstones at different strain rates versus F-T cyclic number: (a) UCS; (b) Deformation modulus

\section{Predicting the deterioration of mechanical properties using decay function models}

\subsection{Decay function model reflecting the strain rate effect}

Accelerated F-T tests in laboratory is valuable to obtain the essential data of rock decay properties, yet insufficient to predict the long-term degradation against F-T weathering. Mutlutürk et al. (2004) proposed a decay function model as Eq.(3), using the decay constant $(\lambda)$ and half-life $\left(N_{1 / 2}\right)$ parameters to express the disintegration rate of rock against cyclic freezing-thawing and heating-cooling.

$$
-(d I / d N)=\lambda N
$$


where $I$ is the rock integrity, $N$ is the number of cycles, $(d I / d N)$ is the disintegration rate and $\lambda$ is the decay constant.

By integrating Eq.(3) between the initial integrity of the rock $\left(I_{0}\right)$ and the integrity after $\mathrm{N}$ cycles $\left(I_{N}\right)$, the decay equation was expressed in exponential form as Eq.(4).

$$
I_{N}=I_{0} e^{-\lambda N}
$$

As a measure of rock durability, the half-life $\left(N_{1 / 2}\right)$ of rock was also defined by Mutlutürk et al. (2004) as the number of cycles necessary to reduce the integrity to half its value. The $N_{1 / 2}$ was inversely related to the decay constant $(\lambda)$ and was calculated by putting $\left(I_{0} / 2\right)$ for $I_{N}$ in Eq. (4), as:

$$
N_{1 / 2}=\ln 2 / \lambda
$$

The model proposed by Mutlutürk et al. (2004) assumes that the decay constant $(\lambda)$ remains unchanged and takes no account of the loading conditions. In fact, loading condition, or strain rate of test specimens is of crucial influence on the strength and deformation properties of rocks, as discussed above. As a result, to take the loading condition into consideration and build a decay model reflecting the strain rate effects is valuable to predict the dynamic mechanical degradation of rocks after a long-term weathering.

Considering the strain rate effects, the decay constant, indicating the relative integrity loss by the action of any single cycle, is the function of strain rate and can be expressed as $\lambda=\lambda(\dot{\varepsilon})$. Based on this assumption, the decay model reflecting the strain rate effect can be expressed in exponential form as Eq.(6).

$$
I_{N}=I_{0} e^{-\lambda(\dot{\varepsilon}) N}
$$

Meanwhile, the half-life $\left(N_{1 / 2}\right)$, as also a function of strain rate $(\dot{\varepsilon})$, can be expressed as

$$
N_{1 / 2}=\ln 2 / \lambda(\dot{\varepsilon})
$$

\subsection{Parameter identification of UCS and deformation modulus decay models}


To investigate the validity of the proposed model and to identify the model parameters, experiment results of static and impact compressions were normalized. For each strain rate group, UCS and deformation modulus of red-sandstone specimens free from F-T were respectively regarded as the normalization reference value, and the corresponding indexes of specimens suffered F-T weathering were normalized.

Regression analysis method was adopted to determine the decay constant $(\lambda(\dot{\varepsilon}))$. For compression tests at five strain rate levels, according to the decay model function, normalized UCS values of red-sandstone, $\frac{U C S_{N}}{U C S_{0}}$, were exponential fitted. The fitted curves and normalized UCS values of red-sandstone at different strain rate were illustrated in Fig.8(a). Similar regression method was applied for the normalized deformation modulus values, $\frac{E_{d_{N}}}{E_{d_{0}}}$, of red-sandstone at different strain rates. The fitted curves were drawn in Fig.8(b) along with the normalized deformation modulus values.
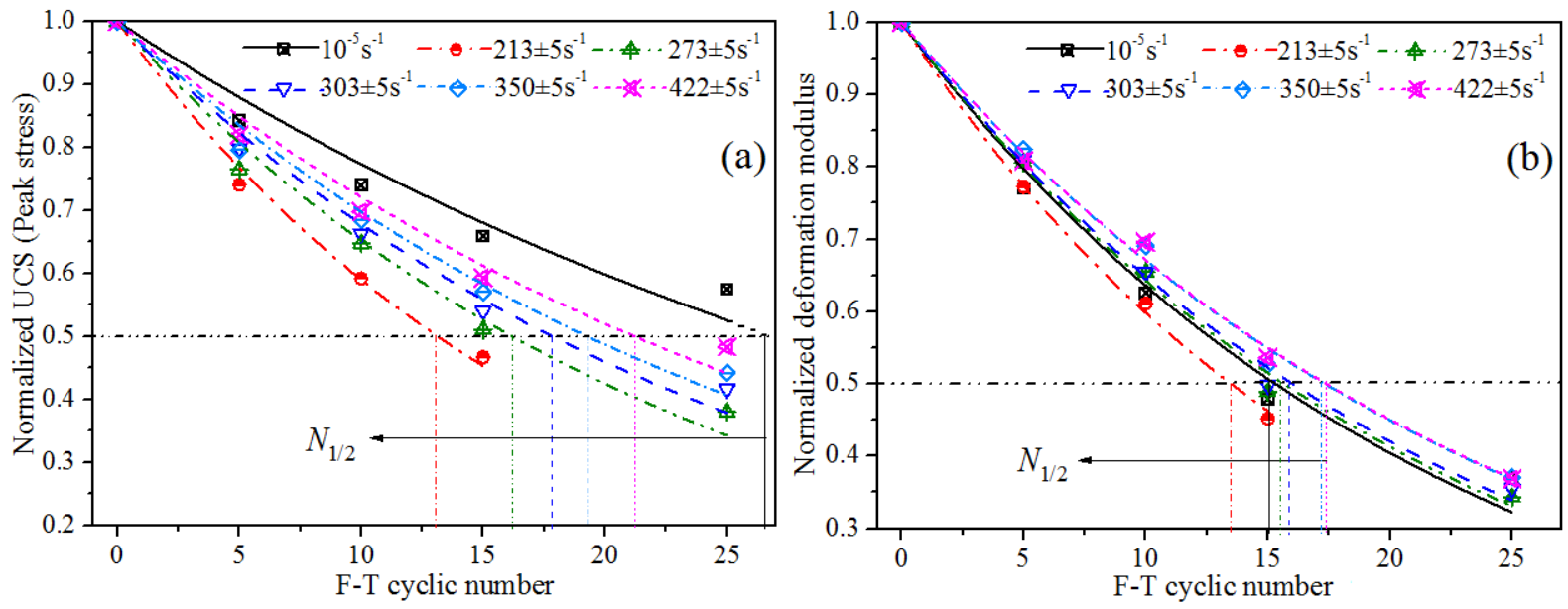

Fig.8. Normalized UCS and deformation modulus of specimens at different strain rates versus F-T cyclic number: (a), normalized UCS; (b), normalized deformation modulus

As illustrated in Fig.8, it is obvious that the decay models fitted the tests results well, which illustrated their effectiveness. For different strain rate groups, UCS and deformation modulus decay models of red-sandstone against F-T cycles were presented in form of Eq. (8). 


$$
\frac{U C S_{N}}{U C S_{0}}=e^{-\lambda(\dot{\varepsilon}) N} ; \quad \frac{E_{d_{N}}}{E_{d_{0}}}=e^{-\lambda(\dot{\varepsilon}) N}
$$

According to the fitted results, the decay constant of UCS and deformation modulus decay models of red-sandstone against F-T cycles were listed in Table 3. With computational formula of Eq.(7), the corresponding half-life values were calculated from decay constant and also listed in Table 3.

Table 3 Decay constant and half-life of UCS and $E_{d}$ of red-sandstone against F-T weathering

\begin{tabular}{cccccc}
\hline \multirow{2}{*}{$\begin{array}{c}\text { Stran rate } \\
\mathrm{s}^{-1}\end{array}$} & \multicolumn{2}{c}{ UCS (Peak stress) } & & \multicolumn{2}{c}{ Deformation modulus $\left(\mathrm{E}_{\mathrm{d}}\right)$} \\
\cline { 2 - 3 } \cline { 5 - 6 } & Decay constant, $\lambda$ & Half-life, $\mathrm{N}_{1 / 2}$ & & Decay constant, $\lambda$ & Half-life, $\mathrm{N}_{1 / 2}$ \\
\hline $10^{-5}$ & 0.0257 & 15.3 & & 0.0453 & 27.0 \\
213 & 0.0528 & 13.5 & & 0.0514 & 13.1 \\
273 & 0.0429 & 15.7 & & 0.0443 & 16.2 \\
303 & 0.0389 & 16.0 & & 0.0433 & 17.8 \\
350 & 0.0360 & 17.3 & & 0.0400 & 19.2 \\
422 & 0.0327 & 17.4 & & 0.0399 & 21.2 \\
\hline
\end{tabular}

\subsection{Strain rate effects on the dynamic mechanical decay against F-T weathering}

UCS and deformation modulus are important mechanical indexes for rock material, the deterioration of which with F-T cycles characterizes the engineering performance aging against F-T weathering. From decay curves of UCS and deformation modulus as illustrated in Fig.8, no obvious regulations or differences were discovered between the static mechanical degradation and the dynamic mechanical degradation of red-sandstone. However, under impact compression condition, changing rules of decay curves with the increase of strain rate were significant that dynamic mechanical properties of red-sandstone degraded more quickly at relatively lower strain rate. Strain rate effects on the long-term decay of red-sandstone against F-T weathering was evaluated using the decay constant and half-life parameters.

The decay constant indicates the mean relative integrity loss by the action of any single cycle. A bigger $\lambda$ value signifies a larger degradation amplitude of mechanical index after a single F-T cycle. Decay constant of UCS and deformation modulus were drawn in Fig.9. 


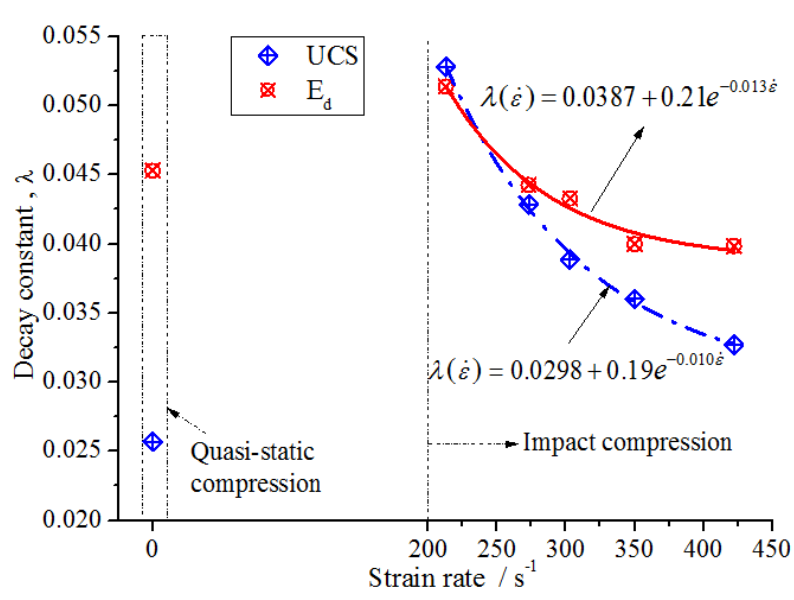

Fig.9. The decay constant of UCS and $E_{d}$ versus strain rate

At most of the strain rate levels, $\mathrm{E}_{\mathrm{d}}$ had a higher decay constant against F-T weathering, except for a little bit strain rate range from $213 \mathrm{~s}^{-1}$ to $235 \mathrm{~s}^{-1}$. Under static compressions, degradation rate of $\mathrm{E}_{\mathrm{d}}$ almost doubled that of UCS. Under dynamic impact compressions, with the strain rate range between $213 \mathrm{~s}^{-1}$ and $422 \mathrm{~s}^{-1}$ in this work, decay constant of both UCS and $E_{d}$ decreased with the increase of stain rate, and decay constant of dynamic UCS reduced faster. Within the strain rate range in this work, dynamic mechanics, UCS and $E_{d}$, of red-sandstone at strain rate about $213 \mathrm{~s}^{-1}$ degraded most quickly against F-T cycles. Exponential functions were used to fit the changing laws of dynamic UCS and $\mathrm{E}_{\mathrm{d}}$ decay constants, with the fitted curves drawn in Fig.9. In this way, decay constants of UCS and $E_{d}$ were expressed as functions of strain rate, respectively as Eq.(9) and Eq.(10).

$$
\begin{aligned}
& \lambda(\dot{\varepsilon})=\left\{\begin{array}{cc}
0.0257, & \dot{\varepsilon}: 10^{-5} s^{-1} \\
0.0298+0.19 e^{-0.010 \dot{\varepsilon}}, & 213 s^{-1}<\dot{\varepsilon}<422 s^{-1}
\end{array}\right. \\
& \lambda(\dot{\varepsilon})=\left\{\begin{array}{cc}
0.0453, & \dot{\varepsilon}: 10^{-5} s^{-1} \\
0.0387+0.21 e^{-0.013 \dot{\varepsilon}}, & 213 s^{-1}<\dot{\varepsilon}<422 s^{-1}
\end{array}\right.
\end{aligned}
$$

By putting Eq.(9) and Eq.(10) into Eq.(8) respectively, the decay models of UCS and $E_{d}$ and the corresponding applicable strain rate ranges were built as Eq.(11) and Eq.(12). 


$$
\begin{aligned}
& \left\{\begin{array}{lr}
\frac{U C S_{N}}{U C S_{0}}=e^{-0.0257 N} & \dot{\varepsilon}: 10^{-5} s^{-1} \\
\frac{U C S_{N}}{U C S_{0}}=e^{-\left(0.0298+0.19 e^{-0.010 \dot{\varepsilon}}\right) N}, & 213 s^{-1}<\dot{\varepsilon}<422 s^{-1}
\end{array}\right. \\
& \left\{\begin{array}{lr}
\frac{\mathrm{E}_{\mathrm{d}_{N}}}{\mathrm{E}_{\mathrm{d}_{0}}}=e^{-0.0453 N}, & \dot{\varepsilon}: 10^{-5} s^{-1} \\
\mathrm{E}_{\mathrm{d}_{N}}=e^{-\left(0.0387+0.21 e^{-0.013 \dot{\varepsilon}}\right) N}, & 213 s^{-1}<\dot{\varepsilon}<422 s^{-1} \\
\mathrm{E}_{\mathrm{d}_{0}}
\end{array}\right.
\end{aligned}
$$

Compared to the decay constant which represents as the disintegration rate of rock against a single F-T cycle, the half-life provides an easy way to get the facts how many F-T cycles are necessary to reduce a mechanical property to its half value, more significant to illustrate the durability against F-T cycles. A high half-life value of rock basically reflects a good performance of resistance to F-T. Half-life values of UCS and deformation modulus were drawn in Fig.10.

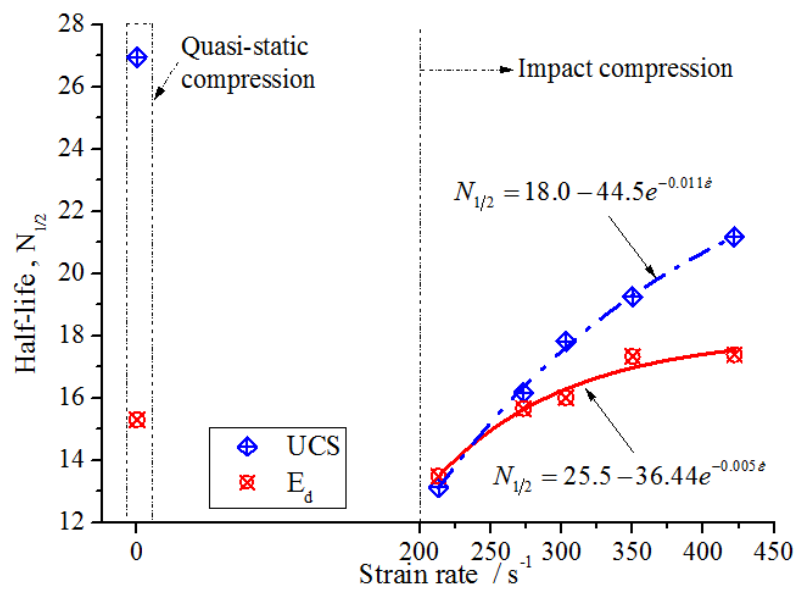

Fig.10. The half-life values of UCS and $E_{d}$ versus strain rate

Clear from the calculation formula of half-life that the $\mathrm{N}_{1 / 2}$ is inversely proportional to the decay constant, and the changing rules of $\mathrm{N}_{1 / 2}$ with the increase of strain rate is also the opposite of the laws of the $\lambda$ value. Under quasi-static compressions, 27 F-T cycles were necessary for red-sandstone to reduce UCS to its half value, nearly twice of the cycles of $E_{d}$. Under dynamic impact compressions, UCS and $E_{d}$ of red-sandstone at strain rate about $213 \mathrm{~s}^{-1}$ degraded quickly and down to the half values after only about 13 F-T cycles, the 
lowest half-life values within the strain rate range in this work. With the increase of strain rate, half-life of dynamic UCS and $\mathrm{E}_{\mathrm{d}}$ increased, yet at different growth rates. At strain rate of $422 \mathrm{~s}^{-1}$, half-life of dynamic UCS was about 22 F-T cycles while that of $\mathrm{E}_{\mathrm{d}}$ was lower, about 17 cycles. Exponential fitting was also carried out between half-life of dynamic UCS and $E_{d}$, and strain rate, with the fitted curves drawn in Fig.10. In this way, half-life values of UCS and $E_{d}$ were expressed as functions of strain rate, respectively as Eq.(13) and Eq.(14).

$$
\begin{gathered}
N_{1 / 2}=\left\{\begin{array}{cc}
27.0, & \dot{\varepsilon}: 10^{-5} s^{-1} \\
18.0-44.5 e^{-0.011 \dot{\varepsilon}}, & 213 s^{-1}<\dot{\varepsilon}<422 s^{-1}
\end{array}\right. \\
N_{1 / 2}=\left\{\begin{array}{cc}
15.3, & \dot{\varepsilon}: 10^{-5} s^{-1} \\
25.5-36.44 e^{-0.005 \dot{\varepsilon}}, & 213 s^{-1}<\dot{\varepsilon}<422 s^{-1}
\end{array}\right.
\end{gathered}
$$

\section{Conclusions}

To study the decay properties of sedimentary rock against a long-term freeze-thaw weathering, physical and mechanical characteristics of red-sandstone specimens free from or after artificial 5, 10, 15, 25 F-T cycles were tested in this work. Taking the strain rate into consideration, static and impact experimental results were analyzed and decay models of uniaxial compression strength (UCS) and deformation modulus $\left(\mathrm{E}_{\mathrm{d}}\right)$ were built. The following conclusions can be drawn from this study.

(1) Cyclic F-T had adverse effect on most of the physico-mechanical properties of red-sandstone. During the F-T weathering process, mineral loss, facture development, volume expansion and cement weakening occurred to specimens, leading to the decrease of P-wave velocity, strength, and modulus.

(2) Strain rate was an important factor influencing the mechanical properties and the F-T induced decay rules of red-sandstone. Red-sandstone had significant strain rate strengthen effect. Under impact compression, both UCS and Ed of red-sandstone increased with the increase of strain rate. At a relative higher strain rate, disintegration rates of both UCS and $\mathrm{E}_{\mathrm{d}}$ were lower than these at a lower strain rate. 
(3) To predict the dynamic mechanical degradation of sedimentary rock after a long-term freeze-thaw weathering, decay function models reflecting strain rate effect were built in this work as Eq.(11) and (12). UCS and $E_{d}$ were selected as the integrity indexes of the decay function models. Based on the experimental results in this work, regression analysis method was adopted to get the changing rules of decay constant $(\lambda)$ and half-life $\left(N_{1 / 2}\right)$ versus strain rate.

\section{Acknowledgments}

The authors acknowledge the financial support of the National Science Foundation of China (No.51378497).

\section{Reference}

Akin M., Ozsan A., 2011. Evaluation of the long-term durability of yellow travertine using accelerated weathering tests. Bull Eng Geol Environ 70, 101-114.

Altindag R., Alyildiz I.S., Onargan T., 2004. Mechanical properties degradation of ignimbrite subjected to recurrent freeze-thaw cycles. Int J Rock Mech Min Sci 41, 1023-1028.

Benavente D., García M.A., Fort R., Ordóñez S., 2004. Durability estimation of porous building stones from pore structure and strength. Eng Geol 74, 113-127.

Bieniawski, Z.T., Bernede, M.J., 1979. Suggested methods for determining the uniaxial compressive strength and deformability of rock materials. International Journal of Rock Mechanics \& Mining Sciences \& Geomechanics Abstracts 16(2), 137-140.

Brown, E.T., 1981. Rock characterization, testing \& monitoring: ISRM suggested methods. Pergamon Press, Oxford, 81-211.

Davidson, G.P., Nye, J.F., 1985. A photoelastic study of ice pressure in rock cracks. Cold Regions Science and Technology 11, 141-153.

Fatih, B., 2012. Predicting mechanical strength loss of natural stones after freeze-thaw in cold regions. Cold Regions Science and Technology 83-84, 98-102.

Frew, D.J., Forrestal, M.J., Chen, W., 2001. A split Hopkinson pressure bar technique to determine compressive stress-strain data for rock materials. Experimental Mechanics 41(1), 40-46. 
Ghobadi, M.H., Babazadeh, R., 2015. Experimental studies on the effects of cyclic freezing-thawing, salt Hettema, Crystallization, and thermal shock on the physical and mechanical characteristics of selected sandstones Rock Mech Rock Eng 48, 1001-1016.

Jamshidi, A., Nikudel, M.R., Khamehchiyan, M., 2013. Predicting the long-term durability of building stones against freeze-thaw using a decay function model. Cold Regions Science and Technology 92, 29-36.

Kahraman, S., 2002. Estimating the direct P-wave velocity value of intact rock from indirect laboratory measurements. Int. J. Rock Mech. Min. Sci. 39, 101-104.

Khanlari G., Sahamieh R.Z., Abdilor Y., 2015. The effect of freeze-thaw cycles on physical and mechanical properties of Upper Red Formation sandstones, central part of Iran. Arab J Geosci 8, 5991-6001.

Lai, Y.M., Zhang, S.M., Yu, W.B., 2012. A new structure to control frost boiling and frost heave of embankments in cold regions. Cold Regions Science and Technology 79-80, 53-66.

Li, X.B., Gu, D.S., 1994. Rock impact dynamics. Changsha: Central South University of Technology Press, 1-42.

Liu, Q.S., Huang, S.B., Kang, Y.S., Liu, X.W., 2015. A prediction model for uniaxial compressive strength of deteriorated rocks due to freeze-thaw. Cold Regions Science and Technology 120, 96-107.

Mutlutürk, M., Altindag, R., Türk, G., 2004. A decay function model for the integrity loss of rock when subjected to recurrent cycles of freezing-thawing and heating-cooling. Int J Rock Mech Min Sci 41, 237-244.

National Development and Reform Commission of the People's Republic of China, 2007. Code for rock tests of hydroelectric and water conservancy engineering (DL/T 5368-2007), 11-12.

Nicholson, H., Dawn, T., Nicholson, F., 2000. Physical deterioration of sedimentary rocks subjected to experimental freezing-thawing weathering. Earth Surface Processes and Landforms 25(12), 1295-1308.

Park, J., Hyun, C.U., Park, H.D., 2015. Changes in microstructure and physical properties of rocks caused by artificial freeze-thaw action. Bull Eng Geol Environ 74, 555-565.

Ruedrich, J., Kirchner, D., Siegesmund, S., 2011. Physical weathering of building stones induced by freeze-thaw action: a laboratory long-term study. Environ Earth Sci 63, 1573-1586.

Shen, Z.J., 2004. Weathering resistant design: An important aspect of future development of geotechnical engineering design. Chinese Journal of Geotechnical Engineering 26(6), 866-869. 
Sousa, L.M.O., del Rio, L.M.S., Calleja, L., de Argandoña, V.G.R., Rey, A.R., 2005. Influence of microfractures and porosity on the physico-mechanical properties and weathering of ornamental granites. Eng. Geol. 77, 153-168.

Tan, X.J., Chen, W.Z., Yang, J.P., Cao, J.J., 2011. Laboratory investigations on the mechanical properties degradation of granite under freeze-thaw cycles. Cold Regions Science and Technology 68, 130-138.

Wang, P., Xu, J.Y., Liu, S., 2015. Staged moduli: A quantitative method to analyze the complete compressive stress-strain response for thermally damaged rock. Rock Mech Rock Eng 48, 1505-1514.

Wen, L., Li, X.B., Wu, Q.H., Weng, L., Su, W., 2015. Study on dynamic strength of granite porphyry under freeze-thaw cycle. Chinese Journal of Rock Mechanics and Engineering 34(7), 1-10.

Xia, K.W., Yao, W., 2015. Dynamic rock tests using split Hopkinson (Kolsky) bar system: A review. Journal of Rock Mechanics and Geotechnical Engineering 7, 27-59.

Yatsu, E., 1988. The nature of weathering: An introduction. Sozosha, Tokyo, p.624.

Yavuz, H., Altindag, R., Sarac, S., Ugur, I., Sengun, N., 2006. Estimating the index properties of deteriorated carbonate rocks due to freeze-thaw and thermal shock weathering. Int. J. Rock Mech. Min. Sci. 43 (5), 767-775.

Zhang, S.J., Lai, Y.M., Zhang, X.F., Pu, Y.B., Yu, W.B., 2004. Study on the damage propagation of surrounding rock from a cold-region tunnel under freeze-thaw cycle condition. Tunnelling and Underground Space Technology 19, 295-302.

Zhang, Q.B., Zhao, J., 2014. A review of dynamic experimental techniques and mechanical behaviour of rock materials. Rock Mech Rock Eng 47, 1411-1478.

Zhou, K.P., Li, B., Li, J.L., Deng, H.W., Bin, F., 2015. Microscopic damage and dynamic mechanical properties of rock under freeze thaw environment. Trans. Nonferrous Met. Soc. China 25, 1254-1261.

Zhou, Y.X., Xia, K., Li, X.B., Li, H.B., Ma, G.W., Zhao, J., Zhou, Z.L., Dai, F., 2012. Suggested methods for determining the dynamic strength parameters and mode-I fracture toughness of rock materials. International Journal of Rock Mechanics \& Mining Sciences 49, 105-112. 